\title{
The Bacteriological and Antimicrobial Susceptibility Profile of Cerebrospinal Fluid Isolates in a Tertiary Hospital, Northeast India
}

\author{
Mandira Ramudamu and Annie B. Khyriem* \\ Department of Microbiology, Neigrihms, Shillong, Meghalaya, India \\ *Corresponding author
}

\section{Keywords}

Bacteriological

Profile,

Antibiogram, CSF

Article Info

Accepted:

10 August 2018

Available Online:

10 September 2018

\section{A B S T R A C T}

CNS infections are life-threatening and significant causes of morbidity and mortality, especially in developing countries. To ensure appropriate therapy, current knowledge of the organisms that cause CNS infection and their antibiotic susceptibility pattern in a particular setting or region is of utmost importance. This study was therefore undertaken to determine bacterial isolates and their antibiogram in the cerebrospinal fluids of patients as seen at Tertiary Hospital. The study was carried out at a tertiary care hospital from June 2016 to December 2016 irrespective of age group. Cerebrospinal fluid (CSF) samples were subjected for bacteriological analysis. Total samples received were 639 out of which 57 samples showed growth. Only 40 pathogens were isolated in culture, which amounts to isolation rate of $7.67 \%$. Gram negative isolation rate $(70 \%)$ was more than gram positive organism (30\%) but the most common organism that was isolated was Enterococcus spp. Most common Gram negative isolate was Acinetobacter baumanii (11.8\%), followed by Escherichia coli $(10.17 \%)$. Gram negative organisms showed higher resistance to beta lactam antibiotics like piperacillin (61.54\%), ampicillin (80\%). cephalosporins like cefotaxime $(81.25 \%)$, cefoperazone $(63.64 \%)$ and ceftriaxone $(50 \%)$ resistance rates were also on the higher side. Cotrimoxazole resistance was also bit high $57.89 \%$. Out of 9 Enterococcus species we isolated, 5 were HLAR (High level Aminoglycoside resistant). Though HLAR Enterococcus species showed 100\% resistance to Penicillin, Ampicillin, Ciprofloxacin but were susceptible to drugs like Vancomycin, Linezolid and Teicoplanin. CNS infections are life-threatening and significant causes of morbidity and mortality, so early management is essential. Since we are encountering resistance to commonly used antibiotics, so microbiological surveillance is important to identify the common pathogens and their antimicrobial susceptibility patterns in order to select the rational empirical antimicrobial therapy based on regional and national data to reduce the emergence of resistant organisms

\section{Introduction}

CNS infections are life-threatening and significant causes of morbidity and mortality, especially in developing countries (Ho Dang Trung et al., 2012; Marchiori et al., 2011).
The cause of CNS infection may vary over time, by geographic region, with age, comorbidities, vaccination programs and the routes by which the pathogens are acquired (Ho Dang Trung et al., 2012). Bacterial infections have been known as the most 
common cause of the CNS infections, meanwhile fungi and mycobacteria are also frequently reported (Vengamma et al., 2014). The pattern of pathogens recovered from CSF culture varies from Gram-positive cocci to multidrug-resistant Gram-negative bacteria depending on geographic region, age, comorbidities, type of neurosurgical procedures, and site of infection (Cucunawangsih et al.,). Antibiotics are usually administered before the laboratory results of CSF culture and sensitivity are available.

To ensure appropriate therapy, current knowledge of the organisms that cause CNS infection and their antibiotic susceptibility pattern in a particular setting or region is of utmost importance. Information obtained from laboratory based surveillance is important in determining the most common aetiology of pathogens. This information is also necessary for improving the clinical management of cases, guiding therapeutic decisions and for designing preventive strategies (Lucy and Temitayo, 2015).

This study was therefore undertaken to determine bacterial isolates and their antibiogram in the cerebrospinal fluids of patients as seen at Tertiary Hospital.

\section{Materials and Methods}

Site of Study: Microbiology department

Duration: 1 year (Jan 2016 - Dec 2016)

Type of Study: Prospective observational study

\section{Methods}

All CSF samples received for aerobic culture and sensitivity from different IPDs in Microbiology department, NEIGRIHMS, Shillong.

\section{Processing of sample}

Directly from the sample, wet mount, India ink preparation and Gram staining was done. Then all these samples were processed for culture and sensitivity by standard method (Mackie and Mccartney, 1996). Media used for culture were 5\% Sheep Blood agar, Chocolate agar, Mac-Conkey agar, Brain Heart Infusion broth (Himedia, Mumbai, India).

All significant isolates were identified by standard procedures and their antimicrobial susceptibility was tested by Kirby Bauer disc diffusion method and interpreted as per Clinical and Laboratory Standards Institute (CLSI, 2015) recommendations (M100-S25 Performance Standards for Antimicrobial Susceptibility Testing).

The routine antimicrobial sensitivity tests were put for the following antibiotics:

Drugs for GPC pathogen

Penicillin (10 units), Ampicillin $(10 \mu \mathrm{g})$, Cefoxitin (30 $\mu \mathrm{g})$, Ciprofloxacin $(5 \mu \mathrm{g})$, Gentamicin $(10 \mu \mathrm{g})$, Cefotaxime $(30 \mu \mathrm{g})$, Chloramphenicol (30 $\mu \mathrm{g}), \quad$ Gentamicin $(120 \mu \mathrm{g})$, Erythromycin $(15 \mu \mathrm{g})$, Clindamycin $(2 \mu \mathrm{g})$, Vancomycin $(30 \mu \mathrm{g}), \quad$ Tetracycline $(30 \mu \mathrm{g})$, Linezolid $(10 \mu \mathrm{g})$, Teicoplanin $(30 \mu \mathrm{g})$, Ofloxacin $(5 \mu \mathrm{g})$ (Himedia, Mumbai, India).

\section{Drugs for GNB pathogen}

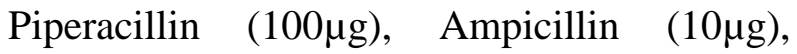
Ciprofloxacin $(5 \mu \mathrm{g})$, Amikacin $(30 \mu \mathrm{g})$, Gentamicin (10 $\mu \mathrm{g})$, Cefotaxime $(30 \mu \mathrm{g})$, Cefoperazone $\quad(75 \mu \mathrm{g}), \quad$ Chloramphenicol $(30 \mu \mathrm{g})$, Cotrimoxazole $25 \mu \mathrm{g}(1.25 / 23.75 \mu \mathrm{g})$, Imipenem $(10 \mu \mathrm{g})$, Meropenem $(10 \mu \mathrm{g})$, Cefop + Sulbacta $(75 \mu \mathrm{g} / 10 \mu \mathrm{g})$, Piperacillin + Tazobactam $(100 \mu \mathrm{g} / 10 \mu \mathrm{g})$, Ofloxacin $(5 \mu \mathrm{g})$, Ceftazidime (30 $\mu \mathrm{g}$ ) (Himedia, Mumbai, India). 


\section{Results and Discussion}

Total of 692 CSF Samples was collected from 401 males and 291 female patient admitted in different wards and ICU of our hospital. Majority of patients were in the age group of 1-20 years and maximum growth was obtained in this group (Fig. 1).

The total number of organisms isolated was 57.

Out of these 57 organisms 17 organism was micrococci which is a normal skin flora and remaining 40 organism was pathogenic organism (Table 1).

Total isolation rate of organism was $8.23 \%$ but isolation rate of pathogenic isolate was just $5.78 \%$. Majority of pathogenic organism that was isolated was gram negative $(70 \%)$ while gram positive isolation rate was just $30 \%$ (Table 2).

Among gram negative isolates gram negative bacilli accounted for maximum percentage whereas only one isolate was gram negative cocci.

Most common isolate was Acinetobacter baumanii followed by Escherichia coli, Enterobacter spp, Klebsiella pneumoniae.

There were few Gram negative bacilli that could not be identified by routine biochemicals and these isolates were more in number compared to Pseudomonas aeruginosa and Haemophilus influenzae.

The only Gram negative cocci isolated was Neisseria meningitidis (Fig. 2).

Enterococcus species was the most common gram positive cocci to be isolated of which HLAR Enterococcus species isolation rate $(8.47 \%)$ was more than Enterococcus species
(6.78\%). Streptococcus pneumoniae (3.39\%) and Streptococcus species (1.69\%) was isolated in 3 cases (Fig. 3).

In our study total samples received were 639 out of which 57 samples showed growth. Only 40 pathogens were isolated in culture, which amounts to isolation rate of $7.67 \%$. Few studies too had similar low isolation rate like 9.6\% (Mengistu et al., 2013), 9.01\% (Singh et al., 2016) and $1.83 \%$ (Lucy and Temitayo, 2015).

Some studies showed slightly high isolation rate of $13.91 \%$ (Gitali et al.,), 15\% (Cucunawangsih et al.,). While very high isolation rate $22.11 \%$ (Devi et al., 2017), 25\% ( $\mathrm{T}$ and J, 2016) was reported in few studies.

Various reasons cited in the literature for a low yield of bacteria on culture are improper technique of lumbar puncture, delay in transport of specimens to the laboratory, Nonavailability of special media for specific pathogens in the emergency setting, Autolysis enzymes in CSF, fastidious nature of pathogen and antibiotic treatment prior to lumbar puncture (Singh et al., 2016).

This might be the reason for low isolation rate in our settings and also we did not access to automated culture system which can significantly increase the sensitivity of culture for diagnosis of infection of sterile body fluids, especially in patients with previous antibiotic therapy (Rezaeizadeh et al., 2012).

Demographic data analysis of patients revealed that they were mainly males $(57.95 \%$ versus $42.05 \%$ for females).

This finding agreed with most of the studies (Lucy and Temitayo, 2015; Singh et al., 2016). Reason for male preponderance for CNS infection is not mentioned in any of the studies. 
Fig.1 Bar diagram showing age distribution and percentage of growth

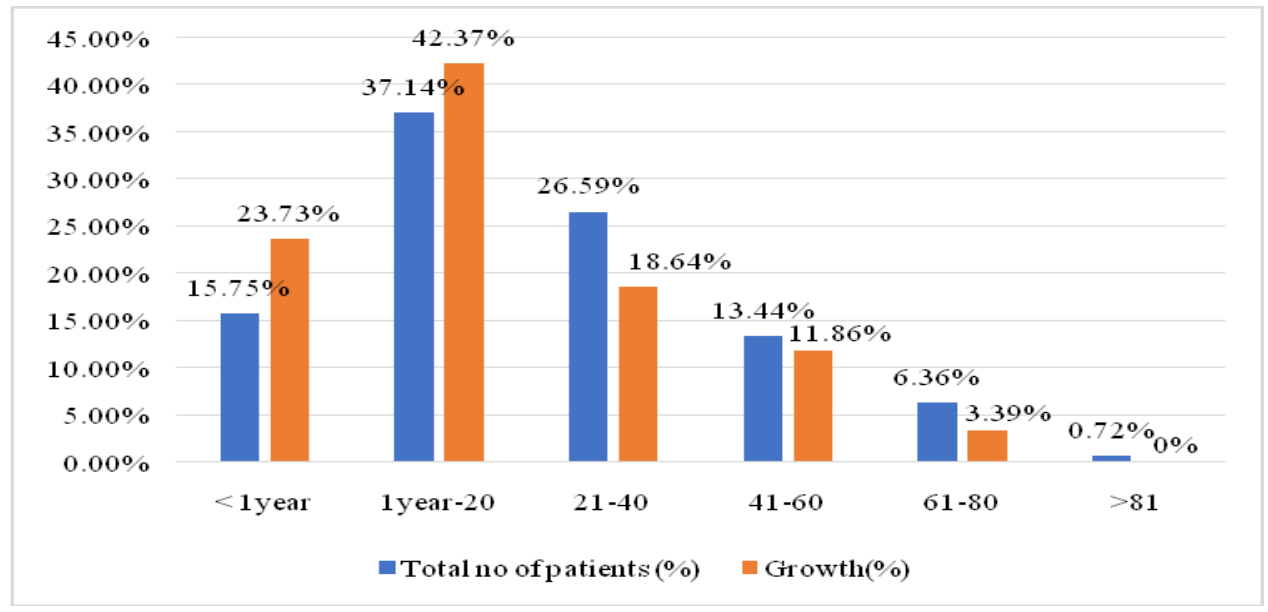

Fig.2 Percentage distribution of gram negative isolates

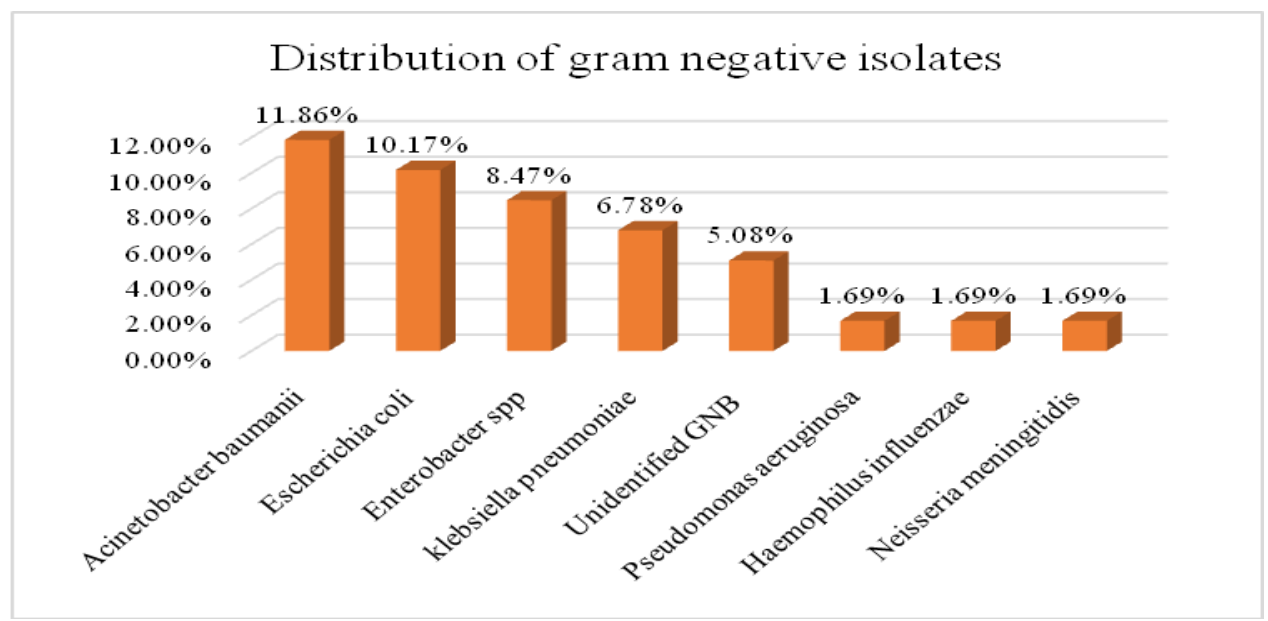

Fig.3 Percentage distribution of gram positive isolates

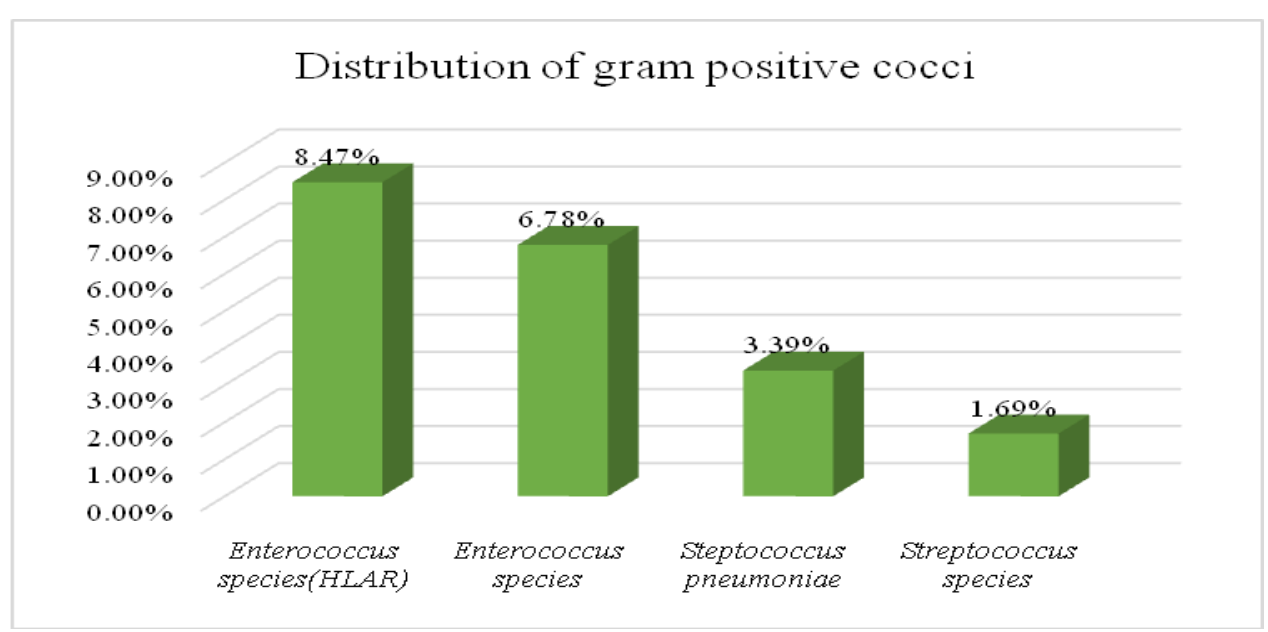


Fig.4 Anti-biogram of gram negative isolates

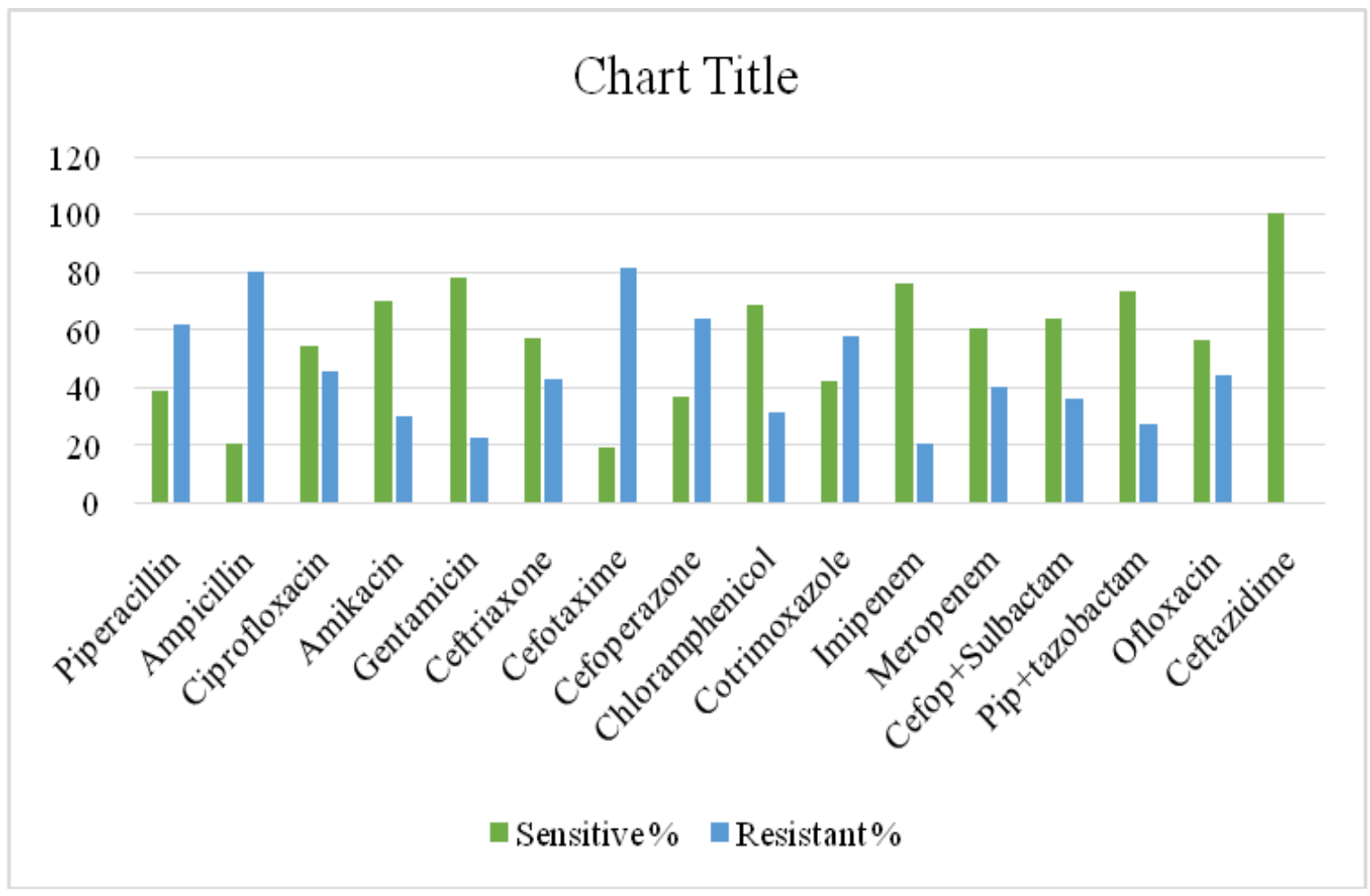

Fig.5 Anti-biogram of gram positive isolates

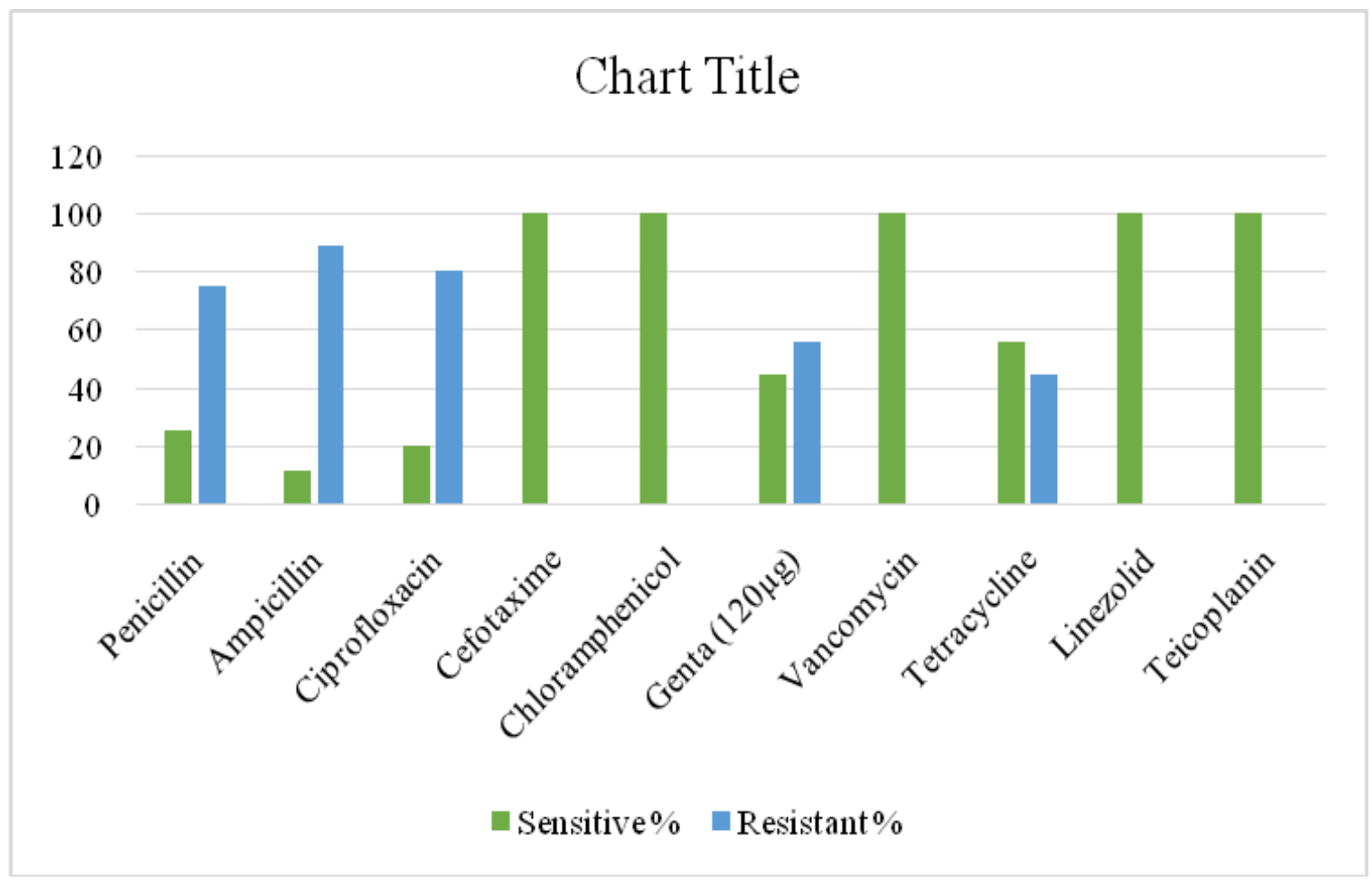


Table.1 Percentage distribution of isolated organism

\begin{tabular}{|c|} 
Organism \\
Micrococci spp \\
\hline Acinetobacter baumanii \\
Escherichia coli \\
\hline Enterobacter spp \\
\hline Enterococcus species (HLAR) \\
\hline Klebsiella pneumoniae \\
\hline Enterococcus species \\
\hline Unidentified GNB \\
\hline Streptococcus pneumoniae \\
\hline Streptococcus species \\
\hline Neisseria meningitidis \\
\hline Pseudomonas aeruginosa \\
\hline Haemophilus influenzae \\
\hline Grand Total \\
\hline
\end{tabular}

\begin{tabular}{|c|c|}
\hline Count of Organism & Percentage \\
\hline 17 & $29.83 \%$ \\
\hline 7 & $12.28 \%$ \\
\hline 6 & $10.53 \%$ \\
\hline 5 & $8.77 \%$ \\
\hline 5 & $8.77 \%$ \\
\hline 4 & $7.02 \%$ \\
\hline 4 & $7.02 \%$ \\
\hline 2 & $5.26 \%$ \\
\hline 1 & $3.51 \%$ \\
\hline 1 & $1.75 \%$ \\
\hline 1 & $1.75 \%$ \\
\hline 1 & $1.75 \%$ \\
\hline $\mathbf{5 7}$ & $1.75 \%$ \\
\hline
\end{tabular}

Table.2 Percentage distribution of pathogenic gram negative and gram positive isolates

\begin{tabular}{|l|l|l|}
\hline $\begin{array}{l}\text { Organism } \\
\text { Gram Negative isolates (28) (70\%) }\end{array}$ & Number & Percentage \\
\hline Acinetobacter baumanii & 7 & $11.86 \%$ \\
\hline Escherichia coli & 6 & $10.17 \%$ \\
\hline Enterobacter spp & 5 & $8.47 \%$ \\
\hline Klebsiella pneumoniae & 4 & $6.78 \%$ \\
\hline GNB under identification & 3 & $5.08 \%$ \\
\hline Pseudomonas aeruginosa & 1 & $1.69 \%$ \\
\hline Haemophilus influenzae & 1 & $1.69 \%$ \\
\hline Neisseria meningitidis & 1 & $1.69 \%$ \\
\hline Gram positive isolates (12) (30\%) & & \\
\hline Enterococcus species (HLAR) & 5 & $8.47 \%$ \\
\hline Enterococcus species & 4 & $6.78 \%$ \\
\hline Streptococcus pneumoniae & 2 & $3.39 \%$ \\
\hline Streptococcus species & 1 & $1.69 \%$ \\
\hline
\end{tabular}

Table.3 Antibiotic resistance pattern of Gram positive isolates

\begin{tabular}{|c|c|c|c|c|}
\hline Agent & $\begin{array}{c}\text { Enterococcus } \\
\text { spp }(\boldsymbol{\%})\end{array}$ & $\begin{array}{c}\text { HLAR } \\
\text { Enterococcus spp } \\
(\boldsymbol{\%})\end{array}$ & $\begin{array}{c}\text { Streptococcus } \\
\text { pneumoniae (\%) }\end{array}$ & $\begin{array}{c}\text { Streptococcus } \\
\text { spp (\%) }\end{array}$ \\
\hline Penicillin & 100 & 100 & 0 & 0 \\
\hline Ampicillin & 75 & 100 & ND & ND \\
\hline Ciprofloxacin & 100 & 100 & 0 & ND \\
\hline Cefotaxime & ND & ND & 0 & 0 \\
\hline Chloramphenicol & ND & ND & ND & 0 \\
\hline Genta (120) & 0 & 100 & ND & ND \\
\hline Vancomycin & 0 & 0 & 0 & ND \\
\hline Tetracycline & 75 & 20 & ND & ND \\
\hline Linezolid & 0 & 0 & ND & ND \\
\hline Teicoplanin & 0 & 0 & ND & ND \\
\hline
\end{tabular}


Table.4 Antibiotic resistance pattern of Gram negative isolates

\begin{tabular}{|c|c|c|c|c|c|c|}
\hline Agent & $\begin{array}{c}\text { Enterobacter } \\
\text { spp (\%) }\end{array}$ & $\begin{array}{c}\text { Escherichia } \\
\text { coli }(\%)\end{array}$ & $\begin{array}{c}\text { Unidentified } \\
\text { GNB }(\%)\end{array}$ & $\begin{array}{c}\text { Haemophilus } \\
\text { influenzae } \\
(\%)\end{array}$ & $\begin{array}{c}\text { Klebsiella } \\
\text { pneumoniae } \\
(\%)\end{array}$ & $\begin{array}{c}\text { Neisseria } \\
\text { meningitidis } \\
(\%)\end{array}$ \\
\hline Piperacillin & 80 & 83.33 & 33.33 & ND & 75 & ND \\
\hline Ampicillin & ND & 100 & 66.67 & 0 & ND & ND \\
\hline Ciprofloxacin & 50 & 60 & 0 & 0 & 75 & ND \\
\hline Amikacin & 66.67 & 50 & 0 & 0 & 0 & ND \\
\hline Gentamicin & 0 & 50 & 33.33 & ND & 0 & ND \\
\hline Ceftriaxone & 100 & ND & ND & 0 & 100 & 0 \\
\hline Cefotaxime & 100 & 80 & 66.67 & ND & 100 & ND \\
\hline Cefoperazone & 50 & 66.67 & 66.67 & ND & 75 & ND \\
\hline Chloramphenicol & 50 & 33.33 & 66.67 & 0 & 0 & 0 \\
\hline Cotrimoxazole & 75 & 80 & 33.33 & 0 & 75 & ND \\
\hline Imipenem & 0 & 16.67 & 0 & ND & 25 & ND \\
\hline Meropenem & 20 & 50 & 0 & ND & 75 & ND \\
\hline Cefop+Sulbactam & 40 & 16.67 & 0 & ND & 75 & ND \\
\hline Pip+tazobactam & 0 & 16.67 & 0 & 0 & 75 & ND \\
\hline Ofloxacin & 40 & 50 & 0 & ND & 75 & ND \\
\hline
\end{tabular}

Table.5 Antibiotic resistance pattern of non-fermenters

\begin{tabular}{|c|c|c|}
\hline Agent & $\begin{array}{c}\text { Acinetobacter } \\
\text { baumanii }\end{array}$ & \begin{tabular}{c} 
Pseudomonas aeruginosa \\
\hline Piperacillin
\end{tabular} \\
\hline Ciprofloxacin & 42.86 & 0 \\
\hline Amikacin & 30 & ND \\
\hline Gentamicin & 0 & 0 \\
\hline Ceftriaxone & 33.33 & ND \\
\hline Cefotaxime & 66.67 & ND \\
\hline Cefoperazone & 60 & ND \\
\hline Cotrimoxazole & 0 & ND \\
\hline Imipenem & 57.14 & 0 \\
\hline Meropenem & 42.86 & 0 \\
\hline Cefop+Sulbactam & 42.86 & ND \\
\hline Pip+tazobactam & 42.86 & 0 \\
\hline Ofloxacin & 42.86 & ND \\
\hline Ceftazidime & ND & 0 \\
\hline
\end{tabular}

The best test to confirm CNS infection is the detection of pathogens in CSF culture (Cucunawangsih et al.,). In our study after
CSF culture both Gram positive and Gram negative organisms was isolated. Though Gram negative isolation rate $(70 \%)$ was more 
than Gram positive organisms $(30 \%)$ but the most common organism that was isolated was Enterococcus spp (Fig. 4 and 5). Once thought to be relatively harmless commensals, enterococci have emerged in recent years as significant pathogens causing infections in both nosocomial and community settings. Though it is very uncommon cause of CNS infection but antimicrobial resistance in Enterococci has been reported increasingly (Wang et al., 2014). So, we cannot ignore these pathogens. Out of 9 Enterococcus species we isolated, 5 was HLAR (High level Aminoglycoside resistant). Though HLAR Enterococcus species showed $100 \%$ resistance to Penicillin, Ampicillin, Ciprofloxacin but showed no any resistance to higher drugs like Vancomycin, Linezolid and Teicoplanin. Similar findings was seen in few studies as well (Rezaeizadeh et al., 2012). Enterococcus species too exhibited similar resistance profile. Apart from Enterococcus species the other Grampositive isolate was Streptococcus pneumoniae, Streptococcus species and these organism did not encounter any resistance. In our study no Staphylococcus aureus and CONS was isolated which is in contrast to some studies which showed Staphylococcus aureus and CONS predominance (Cucunawangsih et al., Gitali et al., Rezaeizadeh et al., 2012). In most of the studies it was gram positive whose isolation rate was more compared to gram negative (Lucy and Temitayo, 2015; Singh et al., 2016; Modi and Anand, 2013) whereas some studies found out that there is a trend towards an increase number of GNB isolates over the period of time (Cucunawangsih et al., Yadegarynia et al., 2014) (Table 3-5).

Most common Gram negative isolate was Acinetobacter baumanii (11.8\%) which is similar to other studies (Cucunawangsih et al., Singh et al., 2016; Yadegarynia et al., 2014), followed by Escherichia coli
(10.17\%). E.coli has also been mentioned as predominant organism in some studies ( $\mathrm{T}$ and J, 2016; Ravikumar et al., 2012).

Gram negative organisms showed higher resistance to beta lactam antibiotics like Piperacillin (61.54\%), Ampicillin (80\%). Cephalosporins like cefotaxime $(81.25 \%)$, cefoperazone $(63.64 \%)$ and Ceftriaxone $(50 \%)$ resistance rates were also on the higher side. Cotrimoxazole resistance was also bit high 57.89\%. High resistance rates to cefotaxime, cefoperazone and ceftriaxone among these organisms are suggestive of presence of extended spectrum $\beta$-lactamases (ESBLs) (Rezaeizadeh et al., 2012). Organisms that express ESBLs are frequently resistant to other antimicrobial agents and treatment of infections caused by these organisms is difficult (Rezaeizadeh et al., 2012). In this study we did not test the presence of ESBL enzymes genetically.

In our study, antibiotic resistance among $E$. coli isolates was frequently identified. High resistance rates to beta lactam antibiotics like Piperacillin, Ampicillin, Cephalosporins like cefotaxime and cefoperazone, Fluoroquinolones like Ciprofloxacin and Ofloxacin were seen. But E.coli showed increased sensitivity to higher antibiotics like carbapenem and combination antibiotics. This resistance problems have been mentioned in few studies as well (Jiang et al., 2017). The reason for this may be due to increased use of all these drugs. Therefore, the use of piperacillin/tazobactam for the treatment of CNS infection caused by E. coli may be helpful. Acinetobacter baumanii showed resistance to most of the antibiotics. Highest resistance was seen against cefotaxime $(66.67 \%)$ followed by cefoperazone $(60 \%)$. Though this resistance rate is bit lower then E.coli but Carbapenem, Imipenem (57.14\%) and combination antibiotic, Ceforperazone + Sulbactam $(42.86 \%)$ and Piperacillin + 
Tazobactam $(42.86 \%)$ resistance rate was on the higher side. E.coli and Acinetobacter baumanii are the two major pathogens in our study. Similar to this other studies also observes an increasing resistance pattern among the major pathogens and is an alarming sign ( $\mathrm{T}$ and $\mathrm{J}, 2016$ ). The reason could be due to the fact that our hospital is a tertiary care centre to which majority of cases referred are pre-treated with antibiotics. The résistance to different group of drugs can be attributed to the rampant and indiscriminate use of antibiotics leading to the development of large scale drug resistance ( $\mathrm{T}$ and $\mathrm{J}, 2016$ ). Other Gram negative bacteria which showed higher resistance pattern was Klebsiella pneumoniae whose isolation rate was $6.78 \%$. Though it showed high resistance rate to almost all the antibiotics but it showed 0\% resistance rate to Aminoglycoside.

CNS infections are life-threatening and significant causes of morbidity and mortality, so early management is essential. Since we are encountering resistance to commonly used antibiotics, so microbiological surveillance is important to identify the common pathogens and their antimicrobial susceptibility patterns in order to select the rational empirical antimicrobial therapy based on regional and national data to reduce the emergence of resistant organisms.

\section{References}

Ho Dang Trung N, Le Thi Phuong T, Wolbers M, Nguyen Van Minh $\mathrm{H}$, Nguyen Thanh V, Van MP, et al., Aetiologies of Central Nervous System Infection in Viet Nam: A Prospective Provincial Hospital-Based Descriptive Surveillance Study. PLoS ONE 2012; 7 (5).

Marchiori PE, Lino AM, Machado LR, Pedalini LM, Boulos M, Scaff M. Neuroinfection survey at a neurological ward in a Brazilian tertiary teaching hospital. Clinics 2011; 66 (6):1021-5.

Vengamma B, Rajguru M, Prasas B.C., Chandra VVR. Central nervous system infections in the intensive care unit. J Clin Sci Res 2014; 3:106-13.

Cucunawangsih, Wiwing V, Lugito NP, Puspitasari vivien. The changing microbiological and antimicrobial susceptibility profile of cerebrospinal fluid organism isolates in a teaching hospital, Tangerang, Indonesia. Int Arab J Antimicrob AgenTs 5 (2:5).

Lucy E YI, and Temitayo O AA. Bacterial Isolates and Antibiogram of Cerebrospinal Fluid of Paediatric Patients as Seen at the University of Port Harcourt Teaching Hospital. J Pharm Biomed Sci 2015; 5 (2):4-9.

Mackie and Mccartney Practical Medical Microbiology 14th/1996.

M100-S25 Performance Standards for Antimicrobial Susceptibility Testing; Twenty-Fifth Informational Supplement. 35 (3).

Mengistu A, Gaeseb J, Uaaka G, Ndjavera C, Kambyambya K, Indongo L, et al., Antimicrobial sensitivity patterns of cerebrospinal fluid (CSF) isolates in Namibia: implications for empirical antibiotic treatment of meningitis. $\mathbf{J}$ Pharm Policy Pract 2013; 6:4.

Singh AK, Kumar A, Gaur V, Jasuja K, Pandey J, Mishra R. Bacteriological profile of acute bacterial meningitis at a tertiary care hospital of North India. Int J Res Med Sci 2016; 4 (10):4387-93.

Gitali B, Barkataki D, Naba HK, Jasmin H, Sharon RR. Bacteriological Profile of Acute Meningitis: A One Year Study in a Tertiary Care Centre in Assam.

Devi U, Bora R, Malik V, Deori R, Gogoi B, Das JK, et al., Bacterial aetiology of neonatal meningitis: A study from north-east India. Indian $\mathrm{J}$ Med Res 2017; 145 (1):138-43. 
$\mathrm{T}$ RS, and $\mathrm{J}$ GBR. Pathological and Microbiological Analysis of Cerebrospinal Fluid in Bacterial Meningitis. Pathol Update Trop J Pathol Microbiol 2016; 2 (03).

Rezaeizadeh G, Pourakbari B, Ashtiani MH, Asgari F, Mahmoudi S, Mamishi S. Antimicrobial Susceptibility of Bacteria Isolated from Cerebrospinal Fluids in an Iranian Referral Pediatric Center, 19982008. Mædica 2012; 7 (2):131-7.

Wang JS, Muzevich K, Edmond MB, Bearman G, Stevens MP. Central nervous system infections due to vancomycin-resistant Enterococci: case series and review of the literature. Int $\mathrm{J}$ Infect Dis 2014; 25 (Supplement C):2631.

Modi S, and Anand AK. Phenotypic Characterization and Antibiogram of CSF Isolates in Acute Bacterial
Meningitis. J Clin Diagn Res JCDR 2013; 7 (12):2704-8.

Yadegarynia D, Gachkar L, Fatemi A, Zali A, Nobari N, Asoodeh M, et al., Changing pattern of infectious agents in postneuro surgical meningitis. Casp J Intern Med 2014; 5 (3):170-5.

Ravikumar R, Dutta BS, K V, T. M N, G A. Infections by Multidrug Resistant Organisms in a Neurosurgical and Neuropsychiatric Care Centre and The Changing antimicrobial susceptibility patterns. J Evol Med Dent Sci 2012; 1 (4):444-52.

Jiang H, Su M, Kui L, Huang H, Qiu L, Li L, et al., Prevalence and antibiotic resistance profiles of cerebrospinal fluid pathogens in children with acute bacterial meningitis in Yunnan province, China, 2012-2015. PLoS ONE 2017; 12 (6).

\section{How to cite this article:}

Mandira Ramudamu and Annie B. Khyriem. 2018. The Bacteriological and Antimicrobial Susceptibility Profile of Cerebrospinal Fluid Isolates in a Tertiary Hospital, Northeast India. Int.J.Curr.Microbiol.App.Sci. 7(09): 1612-1621. doi: https://doi.org/10.20546/ijcmas.2018.709.193 